\title{
A Case Of Vulvar Myiasis
}

\author{
Bishwa Raj Dawadi, ${ }^{1}$ Mingma Temba Sherpa, ${ }^{2}$ Rakshya Shrestha ${ }^{2}$ \\ 'Department of Emergency Medicine, Institute of Medicine, Kathmandu, Nepal, ${ }^{2}$ Department of Medicine, Nepal Medical \\ College Teaching Hospital, Kathmandu, Nepal.
}

\begin{abstract}
Myiasis is occurs in humans and vertebrate animals mostly due to dipterous flies of the genera Chrysomyia and Cochliomyia. There have been reported cases of myiasis of skin, breast, intestine, eyes and ear but very few cases of vulvar myiasis have been reported in the medical literature. We report a case of a 20 years old female with vulvar myiasis. A 20-year old unmarried girl presented to our hospital with complains of vaginal discharge and vulvar irritation for 3 days with evidence of some worms around her vulvar region. Her menstrual history revealed the use of folded cloths instead of sanitary pads during her menstruation. Moreover, she washed those clothes with water and hanged them in the clothesline outside to let them dry before reuse. Examination of the external genitalia multiple ulcers measuring $1 X 1 \mathrm{~cm}$ on the inner surface of the labia minora, heavily infested with large number of maggots. The patient was admitted for 4 days during which she was given antibiotics, analgesics and anti-inflammatory medication. Daily local asepsis of the wound with antiseptic solution (betadine) was done. We removed more than 30 larvae by the fourth day after which no more larvae were seen and she gradually recovered in the following days. It is our opinion that the cause of vulvar myiasis in our patient was her poor sanitary hygiene. Simple measures such as washing clothes thoroughly, drying and ironing of clothes are also necessary to reduce the risk of this human myiasis.
\end{abstract}

Keywords: external genitalia; female; maggots; myiasis.

\section{INTRODUCTION}

Myiasis is the infestation of live humans and other vertebrate animals with dipterous larvae which, at least for a certain period, feed on the host's dead or living tissue, liquid body substances, or ingested food. ${ }^{1}$ Cases of myiasis have been reported numerous times few of which include cutaneous, ${ }^{2}$ breast, ${ }^{3}$ intestinal, ${ }^{1,4}$ aural, ${ }^{5}$ ocular, ${ }^{6}$ etc. Infestation of the vulvar area is relatively rare and to the best of our knowledge there has been only a few reported cases of vulvar myiasis ${ }^{7}$. We present a 20-year-old female with vulvar myiasis. We report a case of vulvar myiasis in an unmarried sexually inactive 20 years old female.

\section{METHODS}

A 20-year old unmarried girl presented to HDCS-TEAM hospital, Dadeldhura with complains of vaginal discharge and vulvar irritation for 3 days. According to the patient, vaginal discharge was white, thin and foul smelling and vulvar irritation had followed shortly thereafter. She denied any history of fever, abdominal pain. History of sexual contact and trauma was negative. Past medical history and drug history were not significant.

On further enquiry, the patient revealed that she had seen some worms around her vulvar region. She patient could not remember the exact date of the last menstrual period but estimated that it would have occurred one to two weeks before. We came to know that she used folded cloths instead of sanitary pads during her

Correspondence: Dr. Bishwa Raj Dawadi, Department of Emergency Medicine, Institute of Medicine, Kathmandu, Nepal. Email: bishwadawadi@gmail.com, Phone : +977-9841226322. 
menstrual period. Moreover, she washed those clothes with water and hanged them in the clothesline outside to let them dry before reuse.

On examination, the patient had stable vitals and no abnormalities were present on systemic examination. On examination of the external genitalia, bilateral edematous and erythematous labia minora was noted. Few larvae were seen on the labial fold. Due to the intense pain on examination, examination under intravenous anaesthesia was performed which showed multiple ulcers measuring $1 \times 1 \mathrm{~cm}$ on the inner surface of the labia minora. The ulcers were heavily infested with large number of larvae, approximately 15-20 in number. Per speculum revealed healthy cervix and digital rectal examination showed no involvement of rectum.

Urine for pregnancy and serologic testing for syphilis was done as part of our routine procedure but HIV testing could not be done due to lack of consent from the guardians. Primitive laboratory setups in our hospital made it impossible for us to perform further cytopathological and microbiological investigations.

\section{RESULTS}

Urine for was negative for beta HCG. The serologic test for syphilis was negative. On the day of presentation, more than 20 maggots were removed with a nontoothed forceps and the wound was carefully cleaned with betadine. We admitted the patient and started empirical treatment with cefuroxime, metronidazole and doxycycline. A tetanus toxoid was administered on admission. The patient remained in the hospital for 4 days during which she was given antibiotics, analgesics and anti-inflammatory medication. Daily local asepsis of the wound with antiseptic solution (betadine) was done. Larvae had to be removed up to the third day of hospitalization. We removed more than 30 larvae by the fourth day after which no more larvae were seen and she gradually recovered in the following days.

\section{DISCUSSION}

Myiasis can be classified into: (a) accidental myiasis (when larvae ingested along with food produce infection), (b) semi-specific myiasis (where the larvae are laid on necrotic tissue in wounds), and (c) obligatory myiasis (when larvae affect undamaged skin) depending on the condition of the involved tissue. Anatomically it can be divided into: cutaneous myiasis, myiasis of external orifices (aural, ocular, nasal, oral, vaginal, and anal), and myiasis of internal organs (intestinal and urinary). ${ }^{8}$ There have been reported cases of myiasis from all over the world, with more cases being reported in tropical, subtropical and warm temperate areas. ${ }^{9}$ Among them many species of dipterous flies of the genera Chrysomyia and Cochliomyia have been reported to be the most important obligatory myiasis producers. ${ }^{10}$ Poor hygiene and sanitation, urinary obstruction and retention and decreased general health have been identified as factors that increase the likelihood of urogenital myiasis 11 and is usually seen patients with low mobility, psychiatric disturbances, acquired immunodeficiency conditions and certain climatic conditions that favor the growth of the files. ${ }^{11,12}$ There is a progressive and continuous necrosis of muscles associated with larval growth and invasion and the pathogenicity results from inflammation and toxin secreted by the larvae, which prevents healing. ${ }^{10}$

The patient was following the tradition of chhaupadi, which is practiced in many areas of Nepal where menstruating females have to spend 4-5 days in a shed away from the family home because they are considered "impure and untouchable" during this period. This practice predisposes them to various infections and diseases. ${ }^{13}$ It is our opinion that the cause of vulvar myiasis in our patient was her poor sanitary hygiene. Her usual practice of washing and drying the sanitary cloth outdoors was the predisposing factor. The flies were attracted to the foul smell caused by improper washing of the sanitary cloth where they laid eggs with the larvae maturing subsequently in her genitalia.

A detailed history and careful examination are important pillars of diagnosis. The goal of treatment is to remove the larva and treat any associated infection with antibiotics. Methods of removing the larva include obstructing the cutaneous orifice thus suffocating the larva, which forces it to wriggle out using substances like oil, petroleum jelly, butter and liquid paraffin. ${ }^{14}$ Educating patients on menstrual hygiene should be emphasized in rural settings with traditional practices. Simple measures such as washing clothes thoroughly, drying and ironing of clothes are also necessary to reduce the risk of this human myiasis. ${ }^{3}$ 


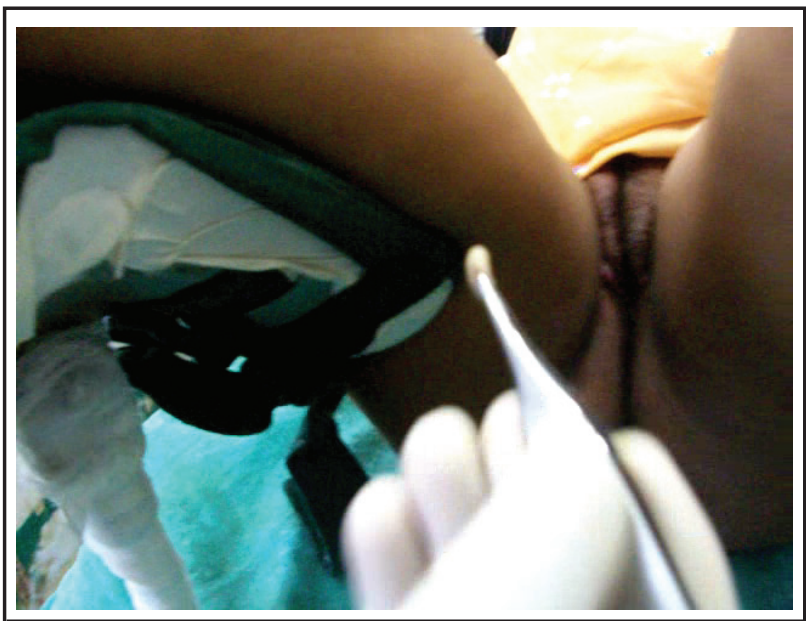

Figure 1. Larvae removed using forceps.

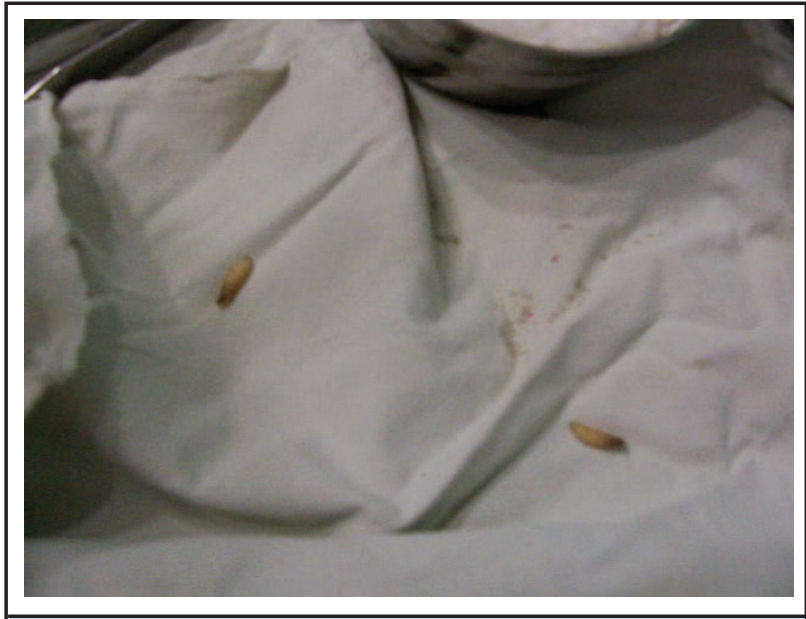

Figure 2. Live Larvae crawling.

\section{REFERENCES}

1. Aguilera A, Cid A, Regueiro BJ, Prieto JM, Noya M. Intestinal myiasis caused by Eristalis tenax. J Clin Microbiol. [Case Reports Letter]. 1999 Sep;37(9):3082.

2. Adehossi E, Parola P. A woman with a skin lesion. Myiasis. Clin Infect Dis. [Case Reports]. 2009 Jun 1;48(11):1584, 628-9.

3. Adisa CA, Mbanaso A. 'Furuncular myiasis of the breast caused by the larvae of the Tumbu fly (Cordylobia anthropophaga)'. BMC Surg. 2004;4:5.

4. Slesak G, Inthalad S, Strobel M, Marschal M, Hall M, Jr., Newton PN. Chromoblastomycosis after a leech bite complicated by myiasis: a case report. BMC Infect Dis. [Case Reports Research Support, Non-U.S. Gov't]. 2011;11:14.

5. Ahmad NW, Ismail A, Jeffery J, Ibrahim S, Hadi AA, Ibrahim $\mathrm{MN}$, et al. Aural myiasis in a neonate in peninsular Malaysia. Parasit Vectors. 2009;2(1):63.

6. Albert MA, Jr., Wells JR. Images in clinical medicine. Ocular myiasis. N Engl J Med. [Case Reports]. 2008 Nov 13;359(20):e25.

7. Passos MR, Carvalho AV, Dutra AL, Goulart Filho RA, Barreto NA, Salles RS, et al. Vulvar myiasis. Infect Dis Obstet Gynecol. [Case Reports]. 1998;6(2):69-71.
8. Bhatt AP, Jayakrishnan A. Oral myiasis: a case report. Int J Paediatr Dent. [Case Reports]. 2000 Mar;10(1):67-70.

9. Delir S HF, Emad M, Ardehali S. Vulvar myiasis due to Wohlfahrtia magnifica. Clin Exp Dermatol. 1999;24(4):279-80.

10. Gopalakrishnan S, Srinivasan R, Saxena SK, Shanmugapriya J. Myiasis in different types of carcinoma cases in southern India. Indian J Med Microbiol. [Case Reports]. 2008 Apr-Jun;26(2):189-92.

11. Hyun DY, Cain MP, Blue-Hnidy DE, Conway JH. Urinary myiasis associated with ureteral stent placements. Pediatr Infect Dis J. [Case Reports]. 2004 Feb;23(2):179-81.

12. Granz W, Schneider D, Schumann H. [Human myiasis in middle Europe]. Z Gesamte Inn Med. 1975 Apr 15;30(8):293-301.

13. Dahal K. Nepalese woman dies after banishment to shed during menstruation. Bmj. 2008;337(a2520).

14. de Barros N, D'Avila MS, de Pace Bauab S, Issa FK, Freitas FJ, KimSJ, et al. Cutaneous myiasis of the breast: mammographic and us features-report of five cases. Radiology. 2001 Feb;218(2):517-20. 